\title{
TITLE:
}

\section{Note: Development of target changeable palm-top pyroelectric $x$-ray tube}

$\operatorname{AUTHOR}(\mathrm{S})$ :

Imashuku, Susumu; Kawai, Jun

\section{CITATION:}

Imashuku, Susumu ...[et al]. Note: Development of target changeable palm-top pyroelectric x-ray tube. Review of Scientific Instruments 2012, 83(1): 016106.

\section{ISSUE DATE:}

2012-01-18

URL:

http://hdl.handle.net/2433/187973

\section{RIGHT:}

(c) 2012 American Institute of Physics. This article may be downloaded for personal use only. Any other use requires prior permission of the author and the American Institute of Physics. 


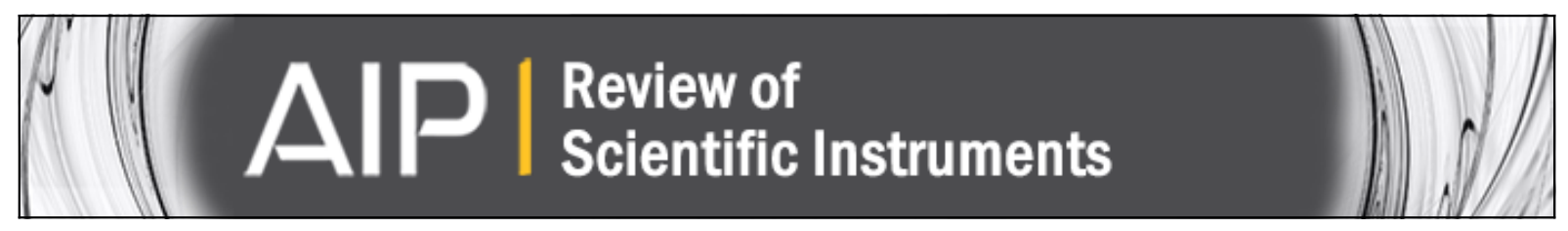

\section{Note: Development of target changeable palm-top pyroelectric x-ray tube}

Susumu Imashuku and Jun Kawai

Citation: Review of Scientific Instruments 83, 016106 (2012); doi: 10.1063/1.3677843

View online: http://dx.doi.org/10.1063/1.3677843

View Table of Contents: http://scitation.aip.org/content/aip/journal/rsi/83/1?ver=pdfcov

Published by the AIP Publishing

Articles you may be interested in

Note: A simple-structured anode exchangeable X-ray tube

Rev. Sci. Instrum. 84, 056108 (2013); 10.1063/1.4807755

Development of a microfocus $x$-ray tube with multiple excitation sources

Rev. Sci. Instrum. 80, 033108 (2009); 10.1063/1.3095551

Calculation of $\mathrm{x}$-ray spectra emerging from an $\mathrm{x}$-ray tube. Part I. Electron penetration characteristics in $\mathrm{x}$-ray targets

Med. Phys. 34, 2164 (2007); 10.1118/1.2734725

Development of a carbon nanotube based microfocus $\mathrm{x}$-ray tube with single focusing electrode

Rev. Sci. Instrum. 77, 054302 (2006); 10.1063/1.2198793

Carbon nanotubes as electron source in an x-ray tube

Appl. Phys. Lett. 78, 2578 (2001); 10.1063/1.1367278

\section{AlP Re-register for Table of Content Alerts}




\title{
Note: Development of target changeable palm-top pyroelectric x-ray tube
}

\author{
Susumu Imashukua) and Jun Kawai \\ Department of Materials Science and Engineering, Kyoto University, Sakyo-ku, Kyoto 606-8501, Japan
}

(Received 20 November 2011; accepted 22 December 2011; published online 18 January 2012)

\begin{abstract}
A target changeable palm-top size x-ray tube was realized using pyroelectric crystal and detachable vacuum flanges. The target metals can be exchanged easily by attaching them on the brass stage with carbon tape. When silver and titanium palates (area: $10 \mathrm{~mm}^{2}$ ) were used as targets, silver $\mathrm{L} \alpha$ and titanium $\mathrm{K}$ lines were clearly observed by bombarding electrons on the targets for $90 \mathrm{~s}$. The intensities were the same or higher than those of previously reported pyroelectric x-ray tubes. Chromium, iron, nickel, copper, and zinc $\mathrm{K}$ lines in the $\mathrm{X}$-ray tube (stainless steel and brass) disappeared by replacing the brass stage and the stainless steel vacuum flange with a carbon stage and a glass tube, respectively. (c) 2012 American Institute of Physics. [doi:10.1063/1.3677843]
\end{abstract}

Recently, we have developed an electron probe microanalyzer (EPMA) with a palm-top size chamber including the electron source and the sample stage using a pyroelectric crystal $\left(\mathrm{LiTaO}_{3}\right)$ as the electron source. ${ }^{1,2}$ One of the notable features of the palm-top EPMA was the ease of exchanging samples because detachable vacuum joints were used for the sample chamber and samples were attached with carbon tape. Applying this feature, in the present study, we present a novel palm-top pyroelectric $\mathrm{x}$-ray tube whose target is easy to exchange.

Brownridge $^{3}$ first invented a pyroelectric $\mathrm{x}$-ray generator using cesium nitrate $\left(\mathrm{CsNO}_{3}\right)$ single crystal and gold foil as a target. Kawai et $a l .{ }^{4}$ investigated the phenomena of $\mathrm{x}$-ray emission due to a charged-up using insulator materials, and found that $\mathrm{x}$-rays were effectively emitted at the pressure of about $1 \mathrm{~Pa}$. Brownridge et al. ${ }^{5}$ reported that intensities of $\mathrm{x}$ rays obtained with a pyroelectric $\mathrm{x}$-ray generator depended on the pressure and that about $1 \mathrm{~Pa}$ was the suitable pressure for generating x-rays. After that, Brownridge et al. ${ }^{6}$ enhanced the performance of the pyroelectric $\mathrm{x}$-ray generator and obtained characteristic $\mathrm{x}$-rays of up to $87 \mathrm{keV}(\mathrm{Pb} \mathrm{K} \alpha)$. They also tried to develop a portable $\mathrm{x}$-ray tube using the pyroelectric crystal. Currently, Amptek Inc. ${ }^{7}$ commercialized the portable xray generator. Geuther $e t a l .{ }^{8}$ fabricated a pyroelectric x-ray generator using a paired-crystal of $\mathrm{LiTaO}_{3}$. Their pyroelectric $\mathrm{x}$-ray generator emitted continuous $\mathrm{x}$-rays with the end point energy of $215 \mathrm{keV}$. Hiro et al. ${ }^{9}$ also fabricated a portable pyroelectric x-ray tube using a paired-crystal of $\mathrm{LiTaO}_{3}$ and obtained $\mathrm{K} \alpha$ lines of copper and zinc with high intensities by pasting brass plate on one $\mathrm{LaTiO}_{3}$ crystal. These pyroelectric $\mathrm{x}$-ray generators and tubes did not require a high-voltage power supply because a high voltage can be obtained by heating or cooling a pyroelectric crystal with a heating resistor or Peltier device. The pyroelectric X-ray tubes emitted x-rays with a battery for operating the Peltier device. It was difficult to exchange targets in the pyroelectric $\mathrm{x}$-ray tubes previously reported because the targets were fixed in the x-ray tubes. In

\footnotetext{
a) Author to whom correspondence should be addressed. Electronic mail: imashuku.susumu.2m@kyoto-u.ac.jp.
}

our pyroelectric $\mathrm{x}$-ray tube, the target metals are easy to exchange.

Photo and schematic view of the pyroelectric x-ray tube in this study are shown in Figs. 1(a) and 1(b), respectively. The pyroelectric $\mathrm{x}$-ray tube was developed by modifying the fabrication procedure of the palm-top EPMA. ${ }^{1}$ In this section, the modified points are summarized. A stainless steel vacuum flange with a $\mathrm{T}$ shape was used for the chamber of the pyroelectric x-ray tube. The wires of the Peltier device were passed through a hole drilled in the blank vacuum flange and the hole was closed with resin. A vacuum pump was directly connected to the vacuum flange with a $\mathrm{T}$ shape through the vacuum hose. The brass rods supporting the brass stage for target metals and the $\mathrm{LiTaO}_{3}$ crystal were attached to the blank vacuum flanges with carbon tape. The center of the vacuum flange with a $\mathrm{T}$ shape had a hole with a diameter of 10 $\mathrm{mm}$. Polyimide tape (Kapton tape) was placed over the hole. A silicon PIN detector (X-123; Amptek Inc.) was set towards the hole as shown in Fig. 1(c). The Peltier device was connected to $3 \mathrm{~V}$ batteries and the $\mathrm{LiTaO}_{3}$ crystal was heated for 2 min. Then, the $\mathrm{LiTaO}_{3}$ crystal was cooled by applying power to the Peltier device and $\mathrm{x}$-ray spectra were measured for 90 s. Titanium (99.5\%) and silver (99.98\%) plates were used as target metals. The targets were $2 \mathrm{~mm}$ in length and $5 \mathrm{~mm}$ in width.

Figure 2(a) shows an energy dispersive x-ray (EDX) spectrum without placing target metals on the brass sample stage. Chromium, iron, nickel, copper, and zinc $\mathrm{K}$ lines were observed. Chromium, iron, and nickel came from the stainless steel vacuum flange with a $\mathrm{T}$ shape. Copper and zinc $\mathrm{K} \alpha$ lines originated from the brass rods and the brass stage. Figure 2(b) shows an EDX spectrum with the silver and titanium plates on the brass sample stage. Silver L $\alpha$ and titanium $\mathrm{K}$ lines were clearly detected in addition to chromium, iron, nickel, copper, and zinc $\mathrm{K}$ lines with 90-s measurement. The intensities of $\mathrm{x}$-rays emitted from the targets in the $\mathrm{x}$ ray tube were the same or higher than those in previously reported x-ray tubes. ${ }^{3,5-9}$ This result indicates that metal plates with areas of $10 \mathrm{~mm}^{2}$ can be used as targets of the pyroelectric $\mathrm{x}$-ray tube we presented. The target metals were also easy to exchange because of the target changeable stage and the 

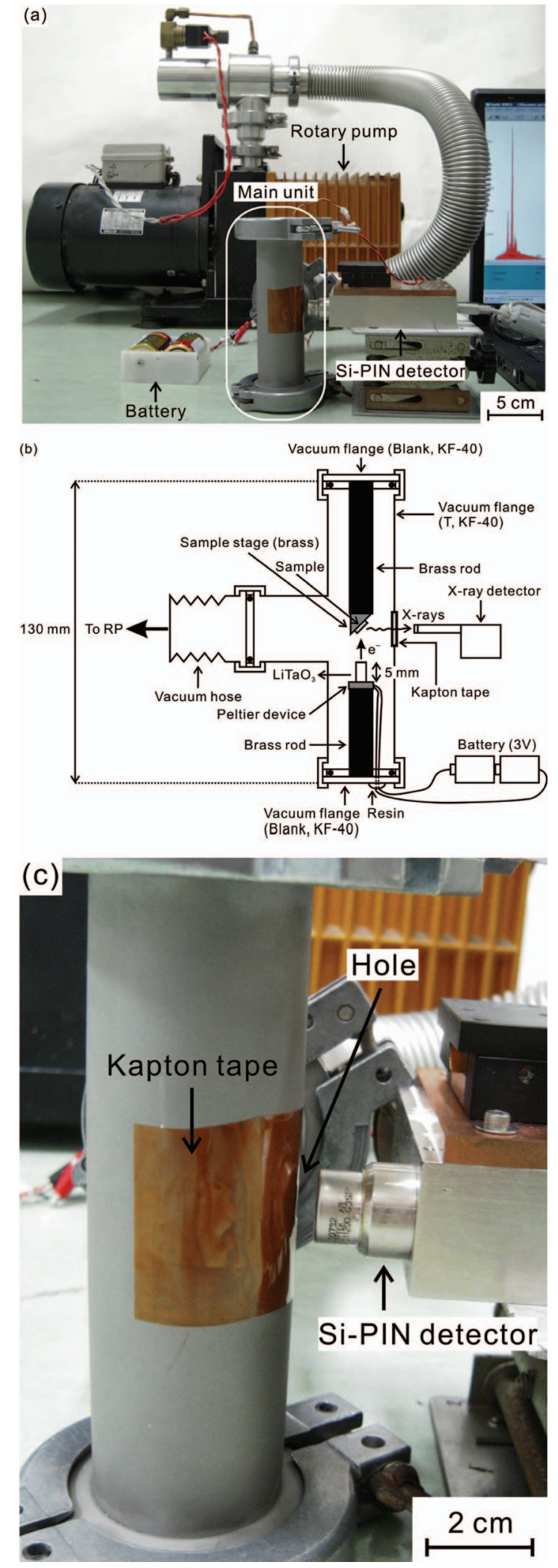

FIG. 1. (Color online) (a) Photo and (b) schematic view of the proposed pyroelectric x-ray tube. (c) Photo of the chamber (ISO Quick release couplings) including the electron source and target with the silicon PIN detector.
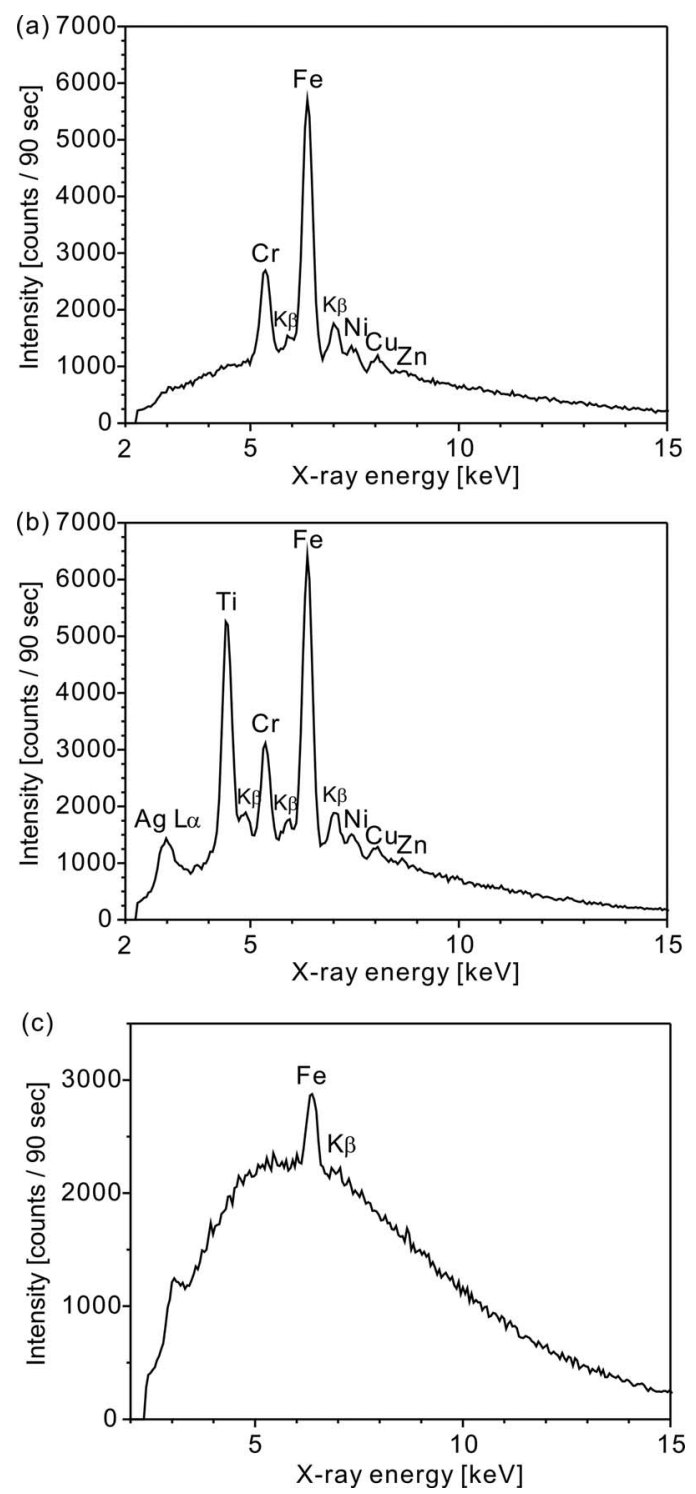

FIG. 2. (a) EDX spectrum without placing target metals on the brass stage. (b) EDX spectrum of titanium and silver plates placed on the brass stage. (c) EDX spectrum of an iron wire whose diameter and length were 0.1 and $5.0 \mathrm{~mm}$, respectively. The brass stage and the stainless steel vacuum flange in the pyroelectric $\mathrm{x}$-ray tube were replaced with a carbon stage and a glass tube.

detachable vacuum flanges in the pyroelectric $x$-ray tube. Thus, the pyroelectric x-ray tube proposed in the present study works as a target changeable $\mathrm{x}$-ray tube. When the brass stage and the stainless steel vacuum flange in the pyroelectric $\mathrm{x}$-ray tube were replaced with a carbon stage and a glass tube, characteristic x-rays from the target metal was only obtained as shown in Fig. 2(c). Thus, it is possible to obtain characteristic $\mathrm{x}$-rays solely from the target metals using the carbon stage and the glass tube. It should be also added that the pyroelectric x-ray tube will become easier to carry if a valve is inserted between the vacuum hose and the vacuum flange with a $\mathrm{T}$ shape and then the vacuum hose is detached after the pressure enough to generate $\mathrm{x}$-rays $(\sim 1 \mathrm{~Pa})$ was obtained.

In conclusion, applying the features of the palm-top EPMA we previously reported in which samples could be exchanged easily, a target changeable palm-top size x-ray tube 
was realized using pyroelectric crystal. The pyroelectric $\mathrm{x}$-ray tube mainly consisted of a $\mathrm{LiTaO}_{3}$ crystal, the brass stage for target metals, detachable stainless steel vacuum flanges, and a vacuum pump. The target metals can be exchanged easily by attaching them to the brass stage with carbon tape. In addition to the advantage of its ease of exchanging the targets, the pyroelectric $\mathrm{x}$-ray tube works with $3 \mathrm{~V}$ batteries. When electrons were bombarded on silver and titanium palates with an area of $10 \mathrm{~mm}^{2}$, silver $\mathrm{L} \alpha$ and titanium $\mathrm{K}$ lines were clearly observed. The intensities were the same or higher than those of previously reported $\mathrm{x}$-ray tubes. We confirmed that the pyroelectric $\mathrm{x}$-ray tube proposed in the present study worked as a target changeable $\mathrm{x}$-ray tube when metal plates with an area of $10 \mathrm{~mm}^{2}$ were used as target metals. Chromium, iron, nickel, copper, and zinc $\mathrm{K}$ lines were additionally detected, having come from metals in the $\mathrm{x}$-ray tube (stainless steel and brass). These characteristic $x$-rays could be removed by replacing the brass stage and the stainless steel vacuum flange with a carbon stage and a glass tube, respectively.
The present study was supported by the Asahi Glass Foundation. Part of the present study was also financially supported by the Murata Science Foundation. We also express our gratitude to Shin-Etsu Chemical Co. Ltd. for the supply of single crystal of a lithium tantalate. We would like to thank the referee of this article for the idea of inserting a valve between the vacuum hose and vacuum flanges.

${ }^{1}$ S. Imashuku, A. Imanishi, and J. Kawai, Anal. Chem. 83, 8363 (2011).

${ }^{2}$ S. Imashuku, A. Imanishi, and J. Kawai, "Palmtop EPMA by Electric Battery," AIP Conf. Proc. (submitted).

${ }^{3}$ J. D. Brownridge, Nature (London) 358, 287 (1992).

${ }^{4}$ J. Kawai, N. Inada, and K. Maeda, Adv. X-Ray Chem. Anal., Jpn (in Japanese) 29, 203 (1997).

5 J. D. Brownridge and S. J. Reboy, Appl. Phys. 86, 640 (1999).

${ }^{6}$ J. D. Brownridge, Appl. Phys. Lett. 85, 1298 (2004).

${ }^{7}$ See http://www.amptek.com/ for the information on the portable pyroelectric X-ray generator.

${ }^{8}$ J. A. Geuther and Y. Danon, J. Appl. Phys. 97, 104916 (2005).

${ }^{9}$ E. Hiro, E. T. Yamamoto, and J. Kawai, Adv. X-Ray Chem. Anal., Jpn. (in Japanese) 41, 195 (2010). 